\title{
Immunological Profiles of The Breast Cancer Microenvironment Represented by Tumor- Infiltrating Lymphocytes and PD-L1 Expression
}

\section{Toru Hanamura}

Department of Breast Oncology, Tokai University School of Medicine

\section{Shigehisa Kitano}

Division of Cancer Immunotherapy Development, Center for Advanced Medical Development, The Cancer Institute Hospital of JFCR

\section{Hiroshi Kagamu}

Division of Respiratory Medicine, Saitama Medical University International Medical Center

\section{Makiko Yamashita}

Division of Cancer Immunotherapy Development, Center for Advanced Medical Development, The Cancer Institute Hospital of JFCR

\section{Mayako Terao}

Department of Breast Oncology, Tokai University School of Medicine

\section{Banri Tsuda}

Department of Breast Oncology, Tokai University School of Medicine

\section{Takuho Okamura}

Department of Breast Oncology, Tokai University School of Medicine

Nobue Kumaki

Department of Pathology, Tokai University, School of Medicine

\section{Katsuto Hozumi}

Department of Immunology, Tokai University School of Medicine

\section{Naoki Harada}

Product Research Department, Chugai Pharmaceutical Co., Ltd.

\section{Takayuki Iwamoto}

Okayama University Hospital, Breast and Endocrine Surgery

\section{Chikako Honda}

Department of General Surgical Science, Gunma University Graduate School of Medicine

\section{Sasagu Kurozumi}

Department of Breast Surgery, International University of Health and Welfare

Naoki Niikura ( $\square$ niikura@is.icc.u-tokai.ac.jp )

Department of Breast Oncology, Tokai University School of Medicine 


\section{Research Article}

Keywords: breast cancer, tumor immunity, microenvironment, programmed cell death 1 ligand 1, flow cytometry

Posted Date: December 7th, 2021

DOI: https://doi.org/10.21203/rs.3.rs-1109400/v1

License: (c) (i) This work is licensed under a Creative Commons Attribution 4.0 International License. Read Full License 


\section{Abstract}

Purpose: Histologically assessed tumor-infiltrating lymphocytes and programmed cell death 1 ligand 1 (hPD-L1) are established prognostic or predictive biomarkers in certain subsets of breast cancer. However, the association with immune response complexity is not fully understood. In this study, the immune cell fractions in breast cancer tissue and blood were evaluated to analyze their association with histologically assessed tumor-infiltrating lymphocytes and PD-L1.

Methods: Forty-five tumor and 18 blood samples were collected from patients with breast cancer. Total leukocyte counts, proportions of 11 types of immune cells, and PD-L1 expression in each cell fraction were evaluated using multicolor flow cytometry. Histologically assessed tumor-infiltrating lymphocytes and PD-L1 were evaluated using hematoxylin and eosin staining and immunohistochemistry, respectively.

Results: The immune cell composition of blood was partly correlated with that of tumor tissue but the abundance ratio of each fraction was different between them. A higher histologically assessed tumorinfiltrating lymphocyte proportion was associated with increased leukocyte infiltration, a higher proportion of $\mathrm{CD} 4^{+}$and $\mathrm{CD} 8^{+} \mathrm{T}$ cells, and a lower proportion of natural killer cells and natural killer $\mathrm{T}$ cells. PD-L1 was highly expressed in the non-B-cell antigen-presenting cell fractions (monocyte/macrophage, nonclassical monocyte, myeloid-derived suppressor, dendritic, and myeloid dendritic cell) in tumors. Histologically assessed PD-L1 positivity reflected PD-L1 expression well in these fractions, as well as increased leukocyte infiltration in tumors.

Conclusion: Our results indicate that histologically assessed tumor-infiltrating lymphocytes reflect differences in immune responses in the tumor microenvironment. Non-B-cell antigen-presenting cell fractions are primarily involved in the PD-L1 pathway in breast cancer microenvironments.

\section{Introduction}

Breast cancer is the most common malignancy among women worldwide. Although progress has been made regarding multimodal treatment comprising surgery, systemic therapy, and radiation therapy, the cure of advanced and recurrent diseases continues to be difficult [1]. The recent success in the clinical use of immune checkpoint inhibitors for multiple cancers has attracted attention in tumor immunology, and an improved understanding of tumor immunology may inform the development of new treatment strategies or effective use of existing therapies [2].

Histologically assessed tumor-infiltrating lymphocytes (hTILs) can provide prognostic information for diverse solid tumor types and may be of value in predicting response to treatment [3]. In breast cancer, amid some controversy, hTIL has been detected more frequently in the triple-negative subtype or human epidermal growth factor receptor-2 (HER-2)-positive subtype than in the luminal subtype [3] and is correlated with clinicopathological factors other than subtypes $[4,5]$. hTIL is associated with prognosis for disease-free and overall survival in triple-negative and HER-2 positive subtypes [4, 6]. Additionally, hTIL has been proposed as a predictor of response to neoadjuvant chemotherapy in all molecular subtypes [7]. 
Programmed cell death 1 ligand 1 (PD-L1) is expressed in immune cells, including T cells, B cells, macrophages, monocytes, and dendritic cells, as well as in tumor cells. PD-L1 can bind to the programmed cell death protein 1 (PD-1) expressed on activated T cells. Interactions with PD-L1 enable PD-1 signaling to counter the activation of $T$ cells during the effector phase of the immune response [8, 9]. Histologically assessed PD-L1 (hPD-L1) is expressed in HER-2 and triple-negative subtypes more frequently than in luminal subtypes, and is correlated with poor prognoses, high histological grades, and lymphatic vessel invasions [10]. hPD-L1 has been established clinically as a predictor of atezolizumab efficacy in triple-negative advanced breast cancer [11]. Recently, different types of immune cell subsets were evaluated primarily via immunohistochemistry (IHC) and found to be associated with various clinicopathological factors or prognoses. These evaluations indicate their clinical significance in breast cancer [12-28] and are summarized in Online Resource Table S1.

Therefore, hTIL and hPD-L1 have been established as biomarkers for breast cancer; recent studies have shifted their attention to the various immune cell subsets that make up hTILs. However, the complexity of the multiple types of immune cells in TIL- or PD-L1-expressing cells is not yet fully understood because of the technical difficulties in detecting multiple types of immune cells in the tissues using conventional IHC. Therefore, we first used multicolor flow cytometry (FCM) to assess the multiple immune cell fractions in breast cancer tissue and blood. We then analyzed the association between hTIL and hPD-L1. By performing a systematic analysis of the immune cell composition, we aimed to show that specific immunological profiles of the breast cancer microenvironment were represented histologically by hTIL and hPD-L1.

\section{Methods}

\section{Patients}

Forty-seven tumor samples from the primary site and 19 matched blood samples were obtained from patients with breast cancer regardless of clinicopathological factors or treatment histories, except for patients with distant metastases or complete clinical responses to neoadjuvant chemotherapy. No patient in this study received irradiation or endocrine therapy before surgery. Following an amendment of the study protocol in July 2016, blood sample collection commenced; therefore, there were cases with no blood samples. Clinicopathological data, including menopausal statuses, histories of preoperative chemotherapy, histological types, invasive tumor sizes, lymph node statuses, lymphatic involvement, vascular involvement, histological grades, estrogen receptor (ER) statuses, progesterone receptor (PgR) statuses, HER-2 statuses, and Ki67 labeling indexes, were collected by reviewing case records.

Histological grades were evaluated according to the method described by Robbins et al. [29]. ER, PgR, and HER-2 statuses were evaluated using IHC staining. The cut-off value for ER and PgR positivity was set at $\geq 10 \%$ [30]. The HER-2 status was determined according to the ASCO CAP guideline 2013 [31]. For reasons mentioned later, 45 tumor samples and 18 blood samples were included in the analysis. The clinicopathological characteristics of the entire cohort and the cohort with blood samples are presented in Online Resource Tables S2 and S3, respectively. 


\section{Tumor-infiltrating lymphocyte/peripheral blood mononuclear cell (PBMC) preparation}

Tumor and blood samples were collected simultaneously during surgery. Tumor samples were mechanically dissociated on ice with $10 \%$ fetal bovine serum-phosphate-buffered saline (FBS-PBS), filtered using a 70 -micron strainer, and washed with 10\% FBS-PBS. All blood samples were collected using a collection tube containing ethylenediaminetetraacetic acid-2Na. For both the tumor and blood samples, mononuclear cell components were separated using density-gradient centrifugation with a Ficoll-Paque PLUS (Cytiva Inc., Tokyo, Japan) according to the manufacturer's instructions. Then, they were suspended in a CELLBANKER I (Takara Bio Inc. Shiga, Japan) and stored in liquid nitrogen.

\section{Flow cytometry analysis}

The cryopreserved TILs and PBMCs were thawed and washed with $10 \%$ FBS-PBS. The cell suspensions were then processed for surface staining with an antibody cocktail (Online Resource Table S4) for 20 min at $4^{\circ} \mathrm{C}$. The cells were washed with PBS containing $2 \%$ FBS and resuspended in CellFix (BD Biosciences, Franklin Lakes, NJ, USA). The stained cells were detected using an LSR II Fortessa with FACS Diva software (BD Biosciences). All analyses were performed using FlowJo software (BD Biosciences). The gating strategy is shown in Online Resource Figure S1. Immune cell fractions were classified into the following according to the definitions shown in Online Resource Table S5: leukocytes, total T cells (Total $\mathrm{T}), \mathrm{CD} 4^{+} \mathrm{T}$ cells $\left(\mathrm{CD} 4^{+} \mathrm{T}\right), \mathrm{CD} 8^{+} \mathrm{T}$ cells $\left(\mathrm{CD} 8^{+} \mathrm{T}\right), \mathrm{B}$ cells $(\mathrm{B})$, monocytes/macrophages $(\mathrm{Mo} / \mathrm{M} \varphi)$, nonclassical monocytes (CD16 ${ }^{+} \mathrm{Mo}$ ), myeloid-derived suppressor cells (MDSCs), dendritic cells (DCs), myeloid dendritic cells (mDCs), natural killer (NK), minor NK cells, and natural killer T cells (NKT). Two cases with a low number of living cells (count $<1000$ ) in the FCM analysis of the tumor tissue were excluded. A blood sample that was identical to one of the two cases was also excluded. The leukocyte density, based on the weight of the tissue fragment and number of viable $\mathrm{CD} 45^{+}$cells, was determined using a previously described method [32]. For the immune cell fraction, we determined both the percentages of each fraction in the leukocytes (\% in leukocytes) and densities based on the weights of the tissue fragments (count/g).

\section{Histological evaluation of tumor immunity-related biomarkers}

We evaluated the histological tumor immunity-related biomarkers, as described previously [33-36]. Briefly, the percentages of stromal TILs were evaluated using 4- $\mu \mathrm{m}$ sections from formalin-fixed specimens stained with hematoxylin and eosin using a light microscope at $\times 200-400$ magnification. Stromal TILs were defined as mononuclear cells localized in the stromal tissue of breast cancer. The stromal TIL count was categorized, according to the International TILs Working Group guideline, into three grades: low (0-10\%), intermediate (10-40\%), and high (40-90\%), and scored from 0 to 2 . The denominator used to determine the TIL grade was the stromal tissue area. PD-L1 expression was assessed using IHC with rabbit monoclonal anti-PD-L1 clone SP142 (prediluted; Spring Bioscience, 
Pleasanton, CA, USA) and the Ventana Benchmark ULTRA auto staining machine. Tumors with $\geq 1 \%$ immune cells with cytoplasmic and/or membrane PD-L1 staining were determined to be PD-L1 positive. Stromal TIL counts and PD-L1 expression were evaluated by two evaluators ( $\mathrm{CH}$ and SK). The histologically assessed TIL and PD-L1 were described as hTIL and hPD-L1, respectively, to distinguish them from the FCM-assessed data. In one case, the hTIL and hPD-L1 could not be evaluated because the remaining tumor tissue was insufficient. Therefore, hTIL and hPD-L1 were analyzed in the remaining 44 patients.

\section{Statistical analysis}

All statistical analyses and graph drawings were performed using GraphPad Prism ver. 9.1.0 software. All analyses for correlation between groups were performed using Spearman's rank correlation coefficient. For the comparison of the paired samples of the tumor and blood, the Wilcoxon test was used. For the comparison of the two unpaired groups, the Mann-Whitney $U$ test was used. A Chi-square test was used to compare clinicopathological factors of the hTILs and hPD-L1. A Fisher's exact test was used when the Chi-square test indicated a significant $P$-value $(P<0.05)$ and there were cells with a sample size of $\leq 5$.

\section{Results}

\section{Distribution of leukocyte and immune cell fraction determined by FCM}

Leukocyte densities based on the weights of the tissue fragments and number of viable CD45+ cells were determined throughout the cohort $(n=45)$. The mean density and interquartile range of the tumorinfiltrating leukocytes were $226 \times 10^{3}$ cells $/ g$ and $80 \times 10^{3}$ to $574 \times 10^{3}$ cells $/ g$, respectively (Figure $1 \mathrm{a}$ ) . For the immune cell fraction in the leukocytes of the tumor tissues (TILs), the main population comprised $\mathrm{CD}^{+} \mathrm{T}, \mathrm{CD}^{+} \mathrm{T}, \mathrm{Mo} / \mathrm{M} \varphi$, and $\mathrm{B}$ (Figure $1 \mathrm{~b}$ and $\mathrm{d}$ ). A similar trend was observed in the leukocyte composition in blood (PBMC), showing that the main population consisted of $\mathrm{CD} 8^{+} \mathrm{T}$ and $\mathrm{CD} 4^{+} \mathrm{T}$ cells (Figures 1c and d).

Immune cell composition of blood is partly correlated with that of tumor tissue but the abundance ratio of each fraction is different between the two

For cases with matched samples of blood and tumor tissue, correlation analysis for the percentages of each of their immune cell fractions was performed (Figure $2 a-l$ ). The proportions of $D C, m D C, N K$, and minor NK in tumor tissue showed a positive correlation with those in blood (Figure $2 \mathrm{~h}-\mathrm{k}$ ). The percentages of each immune cell fraction in tumor tissue (TIL) and blood (PBMC) were compared for the same cases (Figure 3a-I). The proportions of DC, mDC, and minor NK were significantly higher in tumor tissues than in blood (Figure 3h, i, and k). In contrast, the proportions of CD4 ${ }^{+} \mathrm{T}$ and NK cells were significantly lower in tumor tissues than in blood (Figures $3 b$ and j). Although we investigated the relationship between the immune cell composition in blood and hTIL or hPD-L1, no significant 
associations were observed between them (Online Resource Figures S2 and S3). Similarly, no significant associations were identified between hPD-L1 and the FCM assessed PD-L1 positive ratios in the immune cell fraction of blood (Online Resource Figure S4).

Histologically assessed TIL is associated with the degree of leukocyte infiltration in tumor tissue and leukocyte composition

For cases with tumor tissue samples, correlation analysis was performed for the hTIL scores and leukocyte densities (count/g) in the tumor tissues, which were strongly positively correlated with each other (Figure 4a). Furthermore, the hTIL scores showed a positive correlation with the densities (count/g) of almost all immune cell fractions in the tumor tissues, except for NK (Online Resource Figure S5). Correlation analysis was also performed for the hTIL scores and percentages of each immune cell fraction in the tumor tissues. We observed positive correlations between the hTIL scores and percentages of total $\mathrm{T}, \mathrm{CD} 4^{+} \mathrm{T}$, and $\mathrm{CD} 8^{+} \mathrm{T}$ (Figure $4 \mathrm{~b}-\mathrm{d}$ ), but negative correlations between the $\mathrm{hTIL}$ scores and NK and NKT (Figure 4k, m), showing that hTIL was associated with the degree of leukocyte infiltration in tumor tissue and leukocyte composition. There were no correlations between hTIL scores and percentages of $\mathrm{B}, \mathrm{Mo} / \mathrm{M} \varphi, \mathrm{CD} 16+\mathrm{Mo}, \mathrm{MDSC}, \mathrm{DC}, \mathrm{mDC}$ and minor NK (Figure 4e-j and I).

Histologically assessed PD-L1 expression is associated with leukocyte infiltration in tumor tissue and reflects PD-L1 expression in certain immune cell fractions

The percentages of the PD-L1 positive cells in each immune cell fraction were determined for the tumor tissues (TILs) and blood (PBMC) using FCM. Percentages of the PD-L1 positive cells of each immune cell fraction in the tumor tissues are shown in Figure 5a, indicating that PD-L1 is preferentially expressed in non-B-cell antigen-presenting cell fractions such as $\mathrm{Mo} / \mathrm{M} \varphi, \mathrm{CD} 16^{+} \mathrm{Mo}, \mathrm{MDSC}, \mathrm{DC}$, and $\mathrm{mDC}$. For cases with matched samples of blood and tumor tissue, the percentages of the PD-L1 positive cells in each immune cell fraction of the tumor tissues and blood were compared. The PD-L1 positive ratios were significantly higher in tumor tissues than in blood for all lineages except for the lymphoid fractions (Figure $5 b-I$ ). Next, we investigated the relationship between hPD-L1 and the immunological profiles of the tumor tissues. Comparisons between the leukocyte densities (count $/ \mathrm{g}$ ) in the tumor tissues of the hPD-L1 negative and positive cases showed that hPD-L1 positivity was associated with increased leukocyte infiltrations in tumor tissues (Figure 6a). Similarly, hPD-L1 showed a positive correlation with the densities (count/g) of almost all immune cell fractions in the tumor tissues, except B and NK (Online Resource Figure S6). With regard to the immune cell composition in the tumor tissues, although hPD-L1 positivity was associated with a lower percentage of NK and NKT, it was not correlated with the percentages of other lineages (Figure $6 b-m$ ). For tumor tissue samples, PD-L1 positive ratios in each immune cell fraction in the hPD-L1 positive and negative cases were compared. We found that hPD-L1 positivity showed a positive association with the PD-L1 positive ratio in some of the immune cell fractions, including $\mathrm{Mo} / \mathrm{M} \varphi, \mathrm{CD} 16^{+} \mathrm{Mo}, \mathrm{DC}$, and $\mathrm{mDC}$, but not with the other lineages (Figure $7 \mathrm{a}-\mathrm{k}$ ). These data suggest that histologically assessed PD-L1 expression reflects leukocyte infiltration in the tumor tissues and PD-L1 expression in certain immune cell fractions. 


\section{Discussion}

In this study, we evaluated multiple immune cell fractions in both breast cancer tissues and matched blood samples, and then observed a partial correlation in the composition of immune cells at the tumor site and in the peripheral blood. In the comprehensive analysis of the association between each immune cell lineage fraction with hTIL and hPD-L1, we found for the first time that innate immune responses were poor or had disappeared in patients with clinically diagnosed breast cancers, especially in cases with higher hTIL or positive hPD-L1, and that acquired immune responses were active. We also found that nonB-cell antigen-presenting cell fractions were involved primarily in the PD-L1 pathway in breast cancer microenvironments.

To the best of our knowledge, most of the analyses of the immune cell compositions of breast cancer tissues using a multicolor FCM had 10 colors or less [32,37], and there were only two studies with more than 11 colors $[38,39]$. Although the reactivities of the labeled antibodies were not always the same, and a direct comparison was not possible, a similar distribution of the leukocyte infiltrations was observed in the tumor tissue in our study and a previous study with a distribution median of $218 \mathrm{CD} 45^{+} \mathrm{TIL} / \mathrm{mg}$ of tumor tissue (interquartile range: $85-445 \mathrm{CD} 45^{+} \mathrm{TIL} / \mathrm{mg}$ ) [32]. Although there are very few reports of systematic examinations of leukocyte compositions in breast cancer tissue, studies have reported the ratio of total T to be $86 \%$ (mean) [32] or 75\% (median) [38] of the leukocytes (CD45 cells) in breast cancer tissues, suggesting that T cells account for the majority of TILs [40]. In our study, the proportion of total T cells in the leukocytes in the tumors was $57.3 \%$ (mean), which was slightly lower than that in previous reports, probably owing to the difference in the antibody used and gating strategy. In three previous studies, the proportions of $\mathrm{CD}_{19}{ }^{+} \mathrm{B}$ cells in $\mathrm{CD} 45^{+} \mathrm{TIL}$ were found to be $8 \%$ (mean), $4.58 \%$ (median), and approximately $10 \%$ (mean), respectively [32,37,38], which were similar to our results. With regard to other lineages, the findings of a previous study showed that the proportions of $\mathrm{CD} 14^{+} / \mathrm{CD} 40^{+} / \mathrm{CD} 163^{+} \mathrm{M} 2$ macrophages were $0.06 \%$ (median), CD $11 \mathrm{~b}^{+} / \mathrm{CD} 15^{+} / \mathrm{HLA}-\mathrm{DR}-\mathrm{MDSC}$ were $1.19 \%$ (median), and CD56 ${ }^{+}$NK were $2.33 \%$ (median) [38]. However, the studies were few, and the definitions of each lineage did not match those in our study; therefore, valid comparisons could not be made. No comparable reports were found for the remaining lineages.

This is the first study to show an association between the immune cell composition of blood and that of breast cancer tissues. The immune cell composition of blood showed a partial correlation with the tumor tissues and the percentages of the immune cell fractions showed certain differences between the tumor tissues and blood. Although this suggested that the composition of tumor-infiltrating immune cells may be estimated using blood samples, there were significant differences between them.

Although there was a significant difference between the subtypes, hTIL was observed to be correlated with certain clinicopathological factors, including subtypes [3-5], prognoses, and responses to chemotherapy $[4,6,7]$, in breast cancer. In our study, higher hTIL scores were associated with high-grade tumors, ER negativity, higher Ki67 positive ratios, and hPD-L1 positivity (Online Resource Table S6). Numerous studies have also reported that ER-positive breast cancer is the least immune-infiltrated 
subtype, which is consistent with our results $[2,5]$. However, there are certain controversies regarding other clinicopathological factors, and results vary among different studies $[2,4,5,41]$. No studies have systematically assessed the relationship between $\mathrm{hTIL}$ and the immune cell fraction using FCM. In this study, we demonstrated that $\mathrm{hTIL}$ was associated with the degree of leukocyte infiltration in the tumor tissues and leukocyte composition. We found that although there were positive correlations between the hTIL scores and percentages of total $\mathrm{T}, \mathrm{CD} 4^{+} \mathrm{T}$, and $\mathrm{CD} 8^{+} \mathrm{T}$, there were negative correlations between the hTIL scores and NK and NKT. Therefore, we speculate that a higher hTIL reflects the amount of immune cell infiltration, and the state in which acquired immunity is activated, relative to innate immunity in clinically diagnosed breast cancers.

As mentioned previously, PD-L1 plays a significant role in immune tolerance mechanisms [8, 9], and its expression is suggested to reflect ongoing (or active) immune responses in addition to immunosuppression via the PD-1/PD-L1 pathway [39]. hPD-L1 was shown to correlate with certain clinicopathological factors, including subtypes [10]. It is also a clinically approved predictive marker for atezolizumab in triple-negative advanced breast cancer [11]. In the present study, hPD-L1 positivity was associated with ER negativity and relatively high $\mathrm{hTIL}$ scores but not other factors, probably owing to the small cohort size (Online Resource Table S7). Although PD-L1 expression in multiple types of immune cells or tumor cells has been reported [8,9], there is no consensus as to which immune cell fraction is responsible for the substantial function of the PD-L1 pathway in breast cancer. The findings of only one report that evaluated PD-L1 expression in $\mathrm{CD} 4{ }^{+} \mathrm{T}, \mathrm{CD} 8{ }^{+} \mathrm{T}$, and $\mathrm{B}$ cells showed that the overall proportion of the PD-L1 positive TILs was very low and could only be detected in a small number of tumors [39]. In the present study, we found that a substantial proportion of PD-L1 positive immune cells consisted of non-B-cell antigen-presenting cell fractions, such as $\mathrm{Mo} / \mathrm{M} \varphi, \mathrm{CD}_{16}{ }^{+} \mathrm{Mo}, \mathrm{MDSC}, \mathrm{DC}$, and $\mathrm{mDC}$ fractions, and that the PD-L1 positive ratios were significantly higher in tumor tissues than in blood, suggesting that these fractions were involved primarily in the PD-L1 pathway in breast cancer tissue. Additionally, we found that hPD-L1 positive tumors exhibited increased leukocyte infiltration in tumor tissues, and that hPD-L1 reflected PD-L1 expression in Mo/M $\mathrm{M}, \mathrm{CD} 16^{+} \mathrm{Mo}, \mathrm{DC}$, and $\mathrm{mDC}$. These results suggested that hPD-L1 expression indicates the activation status of the immune tolerance mechanism that occurs in non-B-cell antigen-presenting cells in response to increased immune cell infiltration, mainly effector cells that secrete interferon-gamma to induce PD-L1 expression on various cells, into the breast cancer microenvironment.

The FCM findings will be useful in the exploration of new immune-related factors in breast cancer. Briefly, by evaluating the expression of candidate proteins related to tumor immunity by $\mathrm{IHC}$ and analyzing them along with these data, the function of candidate proteins may be verified. We are now focusing on some candidate proteins as immuno-regulatory factors in breast cancer and planning further analyses of the FCM data to validate their immunological functions.

This study had several limitations. First, the number of patients enrolled was relatively small. Second, a pilot study empirically found that the number of cells required for FCM was not sufficient in cases of ERpositive breast cancer, especially in cases with lower Ki67s. Third, cases of small tumor sizes and post-N- 
acetylcysteine with pathological complete response were excluded owing to technical problems in the collection of the tumor tissues. Therefore, there was an inevitable bias in the enrollment of the cases; it differed from the general breast cancer cohort in terms of larger invasive tumor sizes, more ER-negative cases, and higher Ki67 cases (Online Resource Table S2). Finally, although, as mentioned above, the significance of the TIL is suggested to vary between subtypes, a subgroup analysis could not be performed because of the small sample size. In future studies, the collection of more samples and performance of more detailed analyses are recommended.

\section{Conclusions}

In this study, a partial correlation was identified between the composition of immune cells at the tumor site and that in the peripheral blood. A comprehensive analysis of the immune cell fractions revealed the immunological profiles of breast cancer tissue represented by hTIL or hPD-L1. Our findings indicated that hTIL reflected the amount of immune cell infiltration, as well as the state in which acquired immunity is activated relative to innate immunity. Non-B-cell antigen-presenting cell fractions, such as $M o / M \varphi, C D 16^{+}$ Mo, MDSC, DC, and mDCs, were involved primarily in the PD-L1 pathway in breast cancer microenvironments. Additionally, hPD-L1 reflected PD-L1 expression in these immune cell fractions. Our findings provide a basic understanding of the immune response in the breast cancer microenvironment and contribute to the development of tumor immunology.

\section{Abbreviations}

Histologically assessed tumor-infiltrating lymphocytes

hTIL

Human epidermal growth factor receptor-2

HER-2

Programmed cell death 1 ligand 1

PD-L1

Programmed cell death 1

PD-1

Histologically assessed PD-L1 expression

hPD-L1

Immunohistochemistry

IHC

Flow cytometry

FCM

Estrogen receptor

ER

Progesterone receptor

PgR 
Total T cell

Total T

$\mathrm{CD} 4^{+} \mathrm{T}$ cell

$\mathrm{CD} 4^{+} \mathrm{T}$

$\mathrm{CD} 8^{+} \mathrm{T}$ cell

$\mathrm{CD}^{+} \mathrm{T}$

$B$ cell

B

Monocyte/Macrophage

$\mathrm{Mo} / \mathrm{M} \varphi$

Nonclassical monocyte

$\mathrm{CD}^{+} 6^{+} \mathrm{Mo}$

Myeloid-derived suppressor cells

MDSC

Dendritic cell

DC

Myeloid dendritic cell

$\mathrm{mDC}$

Natural killer cell

NK

Natural killer T cell

NKT

\section{Declarations}

Funding: This study was supported by a Grant-in-Aid for Scientific Research from the Ministry of Education, Culture, Sports, Science and Technology, Japan (Project No.18K16266; to NN), and the 2020 Tokai University School of Medicine Research Aid (to TH). This work was also supported by Chugai Pharmaceutical Co., Ltd.

Conflicts of interest: Hiroshi Kagamu has an advisory role in ImmuniT Research Inc. Naoki Harada received a salary from Chugai Pharmaceutical. Shigehisa Kitano received honoraria from Ono Pharmaceutical Co., Bristol-Myers Squibb Co., Ltd., AstraZeneca K.K., Chugai Pharmaceutical Co., Ltd., Pfizer Japan Inc., and MSD Co., Ltd. Hiroshi Kagamu received honoraria from AstraZeneca K.K., Ono Pharmaceutical Co., Ltd., and Bristol-Myers Squibb Co., Ltd. Naoki Niikura received honoraria from AstraZeneca K.K., Daiichi Sankyo Co., Ltd., Pfizer Japan Inc., Eisai Co., Ltd., and Nippon Kayaku Co., Ltd. Shigehisa Kitano received research funding from Astellas Pharma Inc., Gilead Sciences Inc., Eisai Co., Ltd., Regeneron Pharmaceuticals Inc., Boehringer Ingelheim GmgH, Daiichi Sankyo Co., Ltd., Ono Pharmaceutical Co., Takara Bio Inc., PACT Pharma, Inc., Chugai Pharmaceutical Co., Ltd., and MSD Co., 
Ltd. Naoki Niikura received research funding from Chugai Pharmaceutical Co., Ltd. The remaining authors declare no competing interests.

Availability of data and material: The datasets generated during and/or analysed during the current study are available from the corresponding author on reasonable request.

Code availability: Not applicable.

Ethics approval and participant consent: This study was conducted at Tokai University Hospital and approved by the Ethics Committee which conforms to the provisions of the Declaration of Helsinki (Accepted project No. 16R-279). The patients were enrolled from May 2015 to April 2019.

Consent to participate: Written informed consent was obtained from all patients.

Consent for publication: Not applicable.

Acknowledgments: We would like to thank Editage (www.editage.com) for English language editing.

\section{References}

1. Harbeck N, Gnant M (2017) Breast cancer. Lancet (London, England) 389:1134-1150. doi: 10.1016/s0140-6736(16)31891-8

2. Dieci MV, Griguolo G, Miglietta F, Guarneri V (2016) The immune system and hormone-receptor positive breast cancer: Is it really a dead end? Cancer treatment reviews 46:9-19. doi:

10.1016/j.ctrv.2016.03.011

3. Hendry S, Salgado R, Gevaert T, Russell PA, John T, Thapa B, Christie M, van de Vijver K, Estrada MV, Gonzalez-Ericsson PI, Sanders M, Solomon B, Solinas C, Van den Eynden G, Allory Y, Preusser M, Hainfellner J, Pruneri G, Vingiani A, Demaria S, Symmans F, Nuciforo P, Comerma L, Thompson EA, Lakhani S, Kim SR, Schnitt S, Colpaert C, Sotiriou C, Scherer SJ, Ignatiadis M, Badve S, Pierce RH, Viale G, Sirtaine N, Penault-Llorca F, Sugie T, Fineberg S, Paik S, Srinivasan A, Richardson A, Wang Y, Chmielik E, Brock J, Johnson DB, Balko J, Wienert S, Bossuyt V, Michiels S, Ternes N, Burchardi N, Luen SJ, Savas P, Klauschen F, Watson PH, Nelson BH, Criscitiello C, O'Toole S, Larsimont D, de Wind R, Curigliano G, André F, Lacroix-Triki M, van de Vijver M, Rojo F, Floris G, Bedri S, Sparano J, Rimm D, Nielsen T, Kos Z, Hewitt S, Singh B, Farshid G, Loibl S, Allison KH, Tung N, Adams S, Willard-Gallo K, Horlings HM, Gandhi L, Moreira A, Hirsch F, Dieci MV, Urbanowicz M, Brcic I, Korski K, Gaire F, Koeppen H, Lo A, Giltnane J, Rebelatto MC, Steele KE, Zha J, Emancipator K, Juco JW, Denkert C, Reis-Filho J, Loi S, Fox SB (2017) Assessing Tumor-infiltrating Lymphocytes in Solid Tumors: A Practical Review for Pathologists and Proposal for a Standardized Method From the International Immunooncology Biomarkers Working Group: Part 1: Assessing the Host Immune Response, TILs in Invasive Breast Carcinoma and Ductal Carcinoma In Situ, Metastatic Tumor Deposits and Areas for Further Research. Adv Anat Pathol 24:235-251. doi: 10.1097/pap.0000000000000162 
4. Yu X, Zhang Z, Wang Z, Wu P, Qiu F, Huang J (2016) Prognostic and predictive value of tumorinfiltrating lymphocytes in breast cancer: a systematic review and meta-analysis. Clin Transl Oncol 18:497-506. doi: 10.1007/s12094-015-1391-y

5. Solinas C, Carbognin L, De Silva P, Criscitiello C, Lambertini M (2017) Tumor-infiltrating lymphocytes in breast cancer according to tumor subtype: Current state of the art. Breast 35:142-150. doi: 10.1016/j.breast.2017.07.005

6. Mao Y, Qu Q, Chen X, Huang O, Wu J, Shen K (2016) The Prognostic Value of Tumor-Infiltrating Lymphocytes in Breast Cancer: A Systematic Review and Meta-Analysis. PloS one 11:e0152500. doi: 10.1371/journal.pone. 0152500

7. Denkert C, von Minckwitz G, Darb-Esfahani S, Ingold Heppner B, Klauschen F, Furlanetto J, Pfitzner B, Huober J, Schmitt W, Blohmer JU, Kümmel S, Engels K, Lederer B, Schneeweiss A, Hartmann A, Jakisch C, Untch M, Hanusch C, Weber K, Loibl S (2017) Abstract S1-09: Evaluation of tumorinfiltrating lymphocytes (TILs) as predictive and prognostic biomarker in different subtypes of breast cancer treated with neoadjuvant therapy - A metaanalysis of 3771 patients. Cancer research 77:S109. doi: 10.1158/1538-7445.SABCS16-S1-09

8. Pardoll DM (2012) The blockade of immune checkpoints in cancer immunotherapy. Nature reviews. Cancer 12:252-264. doi: 10.1038/nrc3239

9. Cimino-Mathews A, Thompson E, Taube JM, Ye X, Lu Y, Meeker A, Xu H, Sharma R, Lecksell K, Cornish TC, Cuka N, Argani P, Emens LA (2016) PD-L1 (B7-H1) expression and the immune tumor microenvironment in primary and metastatic breast carcinomas. Human pathology 47:52-63. doi: 10.1016/j.humpath.2015.09.003

10. Li X, Li M, Lian Z, Zhu H, Kong L, Wang P, Yu J (2016) Prognostic Role of Programmed Death Ligand1 Expression in Breast Cancer: A Systematic Review and Meta-Analysis. Target Oncol 11:753-761. doi: 10.1007/s11523-016-0451-8

11. Schmid P, Adams S, Rugo HS, Schneeweiss A, Barrios CH, Iwata H, Dieras V, Hegg R, Im SA, Shaw Wright G, Henschel V, Molinero L, Chui SY, Funke R, Husain A, Winer EP, Loi S, Emens LA (2018) Atezolizumab and Nab-Paclitaxel in Advanced Triple-Negative Breast Cancer. The New England journal of medicine 379:2108-2121. doi: 10.1056/NEJMoa1809615

12. Mahmoud SM, Paish EC, Powe DG, Macmillan RD, Grainge MJ, Lee AH, Ellis IO, Green AR (2011) Tumor-infiltrating CD8+ lymphocytes predict clinical outcome in breast cancer. Journal of clinical oncology : official journal of the American Society of Clinical Oncology 29:1949-1955. doi: 10.1200/jco.2010.30.5037

13. Ali HR, Provenzano E, Dawson SJ, Blows FM, Liu B, Shah M, Earl HM, Poole CJ, Hiller L, Dunn JA, Bowden SJ, Twelves C, Bartlett JMS, Mahmoud SMA, Rakha E, Ellis IO, Liu S, Gao D, Nielsen TO, Pharoah PDP, Caldas C (2014) Association between CD8+ T-cell infiltration and breast cancer survival in 12439 patients. Annals of Oncology 25:1536-1543. doi: https://doi.org/10.1093/annonc/mdu191 
14. Gao G, Wang Z, Qu X, Zhang Z (2020) Prognostic value of tumor-infiltrating lymphocytes in patients with triple-negative breast cancer: a systematic review and meta-analysis. BMC cancer 20:179. doi: 10.1186/s12885-020-6668-z

15. Schnellhardt S, Erber R, Büttner-Herold M, Rosahl MC, Ott OJ, Strnad V, Beckmann MW, King L, Hartmann A, Fietkau R, Distel L (2020) Tumour-Infiltrating Inflammatory Cells in Early Breast Cancer: An Underrated Prognostic and Predictive Factor? International journal of molecular sciences 21. doi: 10.3390/ijms21218238

16. Burugu S, Asleh-Aburaya K, Nielsen TO (2017) Immune infiltrates in the breast cancer microenvironment: detection, characterization and clinical implication. Breast cancer (Tokyo, Japan) 24:3-15. doi: 10.1007/s12282-016-0698-z

17. Kim ST, Jeong H, Woo OH, Seo JH, Kim A, Lee ES, Shin SW, Kim YH, Kim JS, Park KH (2013) Tumorinfiltrating lymphocytes, tumor characteristics, and recurrence in patients with early breast cancer. Am J Clin Oncol 36:224-231. doi: 10.1097/COC.0b013e3182467d90

18. Liu S, Foulkes WD, Leung S, Gao D, Lau S, Kos Z, Nielsen TO (2014) Prognostic significance of FOXP3+ tumor-infiltrating lymphocytes in breast cancer depends on estrogen receptor and human epidermal growth factor receptor-2 expression status and concurrent cytotoxic T-cell infiltration. Breast cancer research : BCR 16:432. doi: 10.1186/s13058-014-0432-8

19. Mahmoud SM, Paish EC, Powe DG, Macmillan RD, Lee AH, Ellis IO, Green AR (2011) An evaluation of the clinical significance of FOXP3+ infiltrating cells in human breast cancer. Breast cancer research and treatment 127:99-108. doi: 10.1007/s10549-010-0987-8

20. Gu-Trantien C, Loi S, Garaud S, Equeter C, Libin M, de Wind A, Ravoet M, Le Buanec H, Sibille C, Manfouo-Foutsop G, Veys I, Haibe-Kains B, Singhal SK, Michiels S, Rothé F, Salgado R, Duvillier H, Ignatiadis M, Desmedt C, Bron D, Larsimont D, Piccart M, Sotiriou C, Willard-Gallo K (2013) CD 4区 follicular helper $\mathrm{T}$ cell infiltration predicts breast cancer survival. The Journal of clinical investigation 123:2873-2892. doi: $10.1172 /$ jci67428

21. Mahmoud SM, Lee AH, Paish EC, Macmillan RD, Ellis IO, Green AR (2012) The prognostic significance of $B$ lymphocytes in invasive carcinoma of the breast. Breast cancer research and treatment 132:545-553. doi: 10.1007/s10549-011-1620-1

22. Qiu SQ, Waaijer SJH, Zwager MC, de Vries EGE, van der Vegt B, Schröder CP (2018) Tumorassociated macrophages in breast cancer: Innocent bystander or important player? Cancer treatment reviews 70:178-189. doi: 10.1016/j.ctrv.2018.08.010

23. Zhang QW, Liu L, Gong CY, Shi HS, Zeng YH, Wang XZ, Zhao YW, Wei YQ (2012) Prognostic significance of tumor-associated macrophages in solid tumor: a meta-analysis of the literature. PloS one 7:e50946. doi: 10.1371/journal.pone.0050946

24. Li F, Zhao Y, Wei L, Li S, Liu J (2018) Tumor-infiltrating Treg, MDSC, and IDO expression associated with outcomes of neoadjuvant chemotherapy of breast cancer. Cancer Biol Ther 19:695-705. doi: $10.1080 / 15384047.2018 .1450116$ 
25. de la Cruz-Merino L, Barco-Sánchez A, Henao Carrasco F, Nogales Fernández E, Vallejo Benítez A, Brugal Molina J, Martínez Peinado A, Grueso López A, Ruiz Borrego M, Codes Manuel de Villena M, Sánchez-Margalet V, Nieto-García A, Alba Conejo E, Casares Lagar N, Ibáñez Martínez J (2013) New insights into the role of the immune microenvironment in breast carcinoma. Clin Dev Immunol 2013:785317. doi: $10.1155 / 2013 / 785317$

26. Lee H, Lee HJ, Song IH, Bang WS, Heo SH, Gong G, Park IA (2018) CD11c-Positive Dendritic Cells in Triple-negative Breast Cancer. In Vivo 32:1561-1569. doi: 10.21873/invivo.11415

27. Tsuge T, Yamakawa $M$, Tsukamoto $M(2000)$ Infiltrating dendritic/Langerhans cells in primary breast cancer. Breast cancer research and treatment 59:141-152. doi: 10.1023/a:1006396216933

28. Rathore AS, Goel MM, Makker A, Kumar S, Srivastava AN (2014) Is the tumor infiltrating natural killer cell (NK-TILs) count in infiltrating ductal carcinoma of breast prognostically significant? Asian Pac J Cancer Prev 15:3757-3761. doi: 10.7314/apjcp.2014.15.8.3757

29. Robbins P, Pinder S, de Klerk N, Dawkins H, Harvey J, Sterrett G, Ellis I, Elston C (1995) Histological grading of breast carcinomas: a study of interobserver agreement. Human pathology 26:873-879.

30. Allred DC, Harvey JM, Berardo M, Clark GM (1998) Prognostic and predictive factors in breast cancer by immunohistochemical analysis. Modern pathology : an official journal of the United States and Canadian Academy of Pathology, Inc 11:155-168.

31. Wolff AC, Hammond ME, Hicks DG, Dowsett M, McShane LM, Allison KH, Allred DC, Bartlett JM, Bilous M, Fitzgibbons P, Hanna W, Jenkins RB, Mangu PB, Paik S, Perez EA, Press MF, Spears PA, Vance GH, Viale G, Hayes DF (2013) Recommendations for human epidermal growth factor receptor 2 testing in breast cancer: American Society of Clinical Oncology/College of American Pathologists clinical practice guideline update. Journal of clinical oncology : official journal of the American Society of Clinical Oncology 31:3997-4013. doi: 10.1200/jco.2013.50.9984

32. Buisseret L, Garaud S, de Wind A, Van den Eynden G, Boisson A, Solinas C, Gu-Trantien C, Naveaux C, Lodewyckx JN, Duvillier H, Craciun L, Veys I, Larsimont D, Piccart-Gebhart M, Stagg J, Sotiriou C, Willard-Gallo K (2017) Tumor-infiltrating lymphocyte composition, organization and PD-1/ PD-L1 expression are linked in breast cancer. Oncoimmunology 6:e1257452. doi:

10.1080/2162402x.2016.1257452

33. Kurozumi S, Inoue K, Matsumoto H, Fujii T, Horiguchi J, Oyama T, Kurosumi M, Shirabe K (2019) Clinicopathological values of PD-L1 expression in HER2-positive breast cancer. Scientific reports 9:16662. doi: 10.1038/s41598-019-52944-6

34. Kurozumi S, Kaira K, Matsumoto H, Hirakata T, Yokobori T, Inoue K, Horiguchi J, Katayama A, Koshi H, Shimizu A, Oyama T, Sloan EK, Kurosumi M, Fujii T, Shirabe K (2019) $\beta$ (2)-Adrenergic receptor expression is associated with biomarkers of tumor immunity and predicts poor prognosis in estrogen receptor-negative breast cancer. Breast cancer research and treatment 177:603-610. doi: 10.1007/s10549-019-05341-6

35. Kurozumi S, Matsumoto H, Kurosumi M, Inoue K, Fujii T, Horiguchi J, Shirabe K, Oyama T, Kuwano H (2019) Prognostic significance of tumour-infiltrating lymphocytes for oestrogen receptor-negative 
breast cancer without lymph node metastasis. Oncol Lett 17:2647-2656. doi: 10.3892/ol.2019.9938

36. Salgado R, Denkert C, Demaria S, Sirtaine N, Klauschen F, Pruneri G, Wienert S, Van den Eynden G, Baehner FL, Penault-Llorca F, Perez EA, Thompson EA, Symmans WF, Richardson AL, Brock J, Criscitiello C, Bailey H, Ignatiadis M, Floris G, Sparano J, Kos Z, Nielsen T, Rimm DL, Allison KH, ReisFilho JS, Loibl S, Sotiriou C, Viale G, Badve S, Adams S, Willard-Gallo K, Loi S (2015) The evaluation of tumor-infiltrating lymphocytes (TILs) in breast cancer: recommendations by an International TILs Working Group 2014. Annals of oncology : official journal of the European Society for Medical Oncology 26:259-271. doi: 10.1093/annonc/mdu450

37. Garaud S, Buisseret L, Solinas C, Gu-Trantien C, de Wind A, Van den Eynden G, Naveaux C, Lodewyckx JN, Boisson A, Duvillier H, Craciun L, Ameye L, Veys I, Paesmans M, Larsimont D, PiccartGebhart M, Willard-Gallo K (2019) Tumor infiltrating B-cells signal functional humoral immune responses in breast cancer. JCl Insight 5. doi: 10.1172/jci.insight.129641

38. Duechler M, Peczek L, Zuk K, Zalesna I, Jeziorski A, Czyz M (2014) The heterogeneous immune microenvironment in breast cancer is affected by hypoxia-related genes. Immunobiology 219:158165. doi: $10.1016 /$ j.imbio.2013.09.003

39. Solinas C, Garaud S, De Silva P, Boisson A, Van den Eynden G, de Wind A, Risso P, Rodrigues Vitória J, Richard F, Migliori E, Noël G, Duvillier H, Craciun L, Veys I, Awada A, Detours V, Larsimont D, PiccartGebhart M, Willard-Gallo K (2017) Immune Checkpoint Molecules on Tumor-Infiltrating Lymphocytes and Their Association with Tertiary Lymphoid Structures in Human Breast Cancer. Frontiers in immunology 8:1412. doi: 10.3389/fimmu.2017.01412

40. Whitford P, Mallon EA, George WD, Campbell AM (1990) Flow cytometric analysis of tumour infiltrating lymphocytes in breast cancer. British journal of cancer 62:971-975. doi:

10.1038/bjc. 1990.419

41. Stanton SE, Disis ML (2016) Clinical significance of tumor-infiltrating lymphocytes in breast cancer. J Immunother Cancer 4:59. doi: 10.1186/s40425-016-0165-6

\section{Figures}

\section{Figure 1}

Summary of the distribution of the leukocytes and immune cell fractions determined using flow cytometry (FCM). Tumor and blood samples were assessed using multicolor FCM. The leukocyte and 11 types of immune cell fraction in the samples were determined according to the definitions in the Materials and Methods section. (a) The distribution of leukocyte density (count/g) determined using MCF for 45 breast tumors is shown graphically with the medians, 25th percentile and 75th percentile. (b, c) Percentages of each immune cell fraction are shown for the tumors $(n=45)$ and blood samples $(n=18)$ 
using Tukey box plots. (d) Statistical values are summarized for the percentages of each immune cell fraction in the tumor tissues $(n=45)$

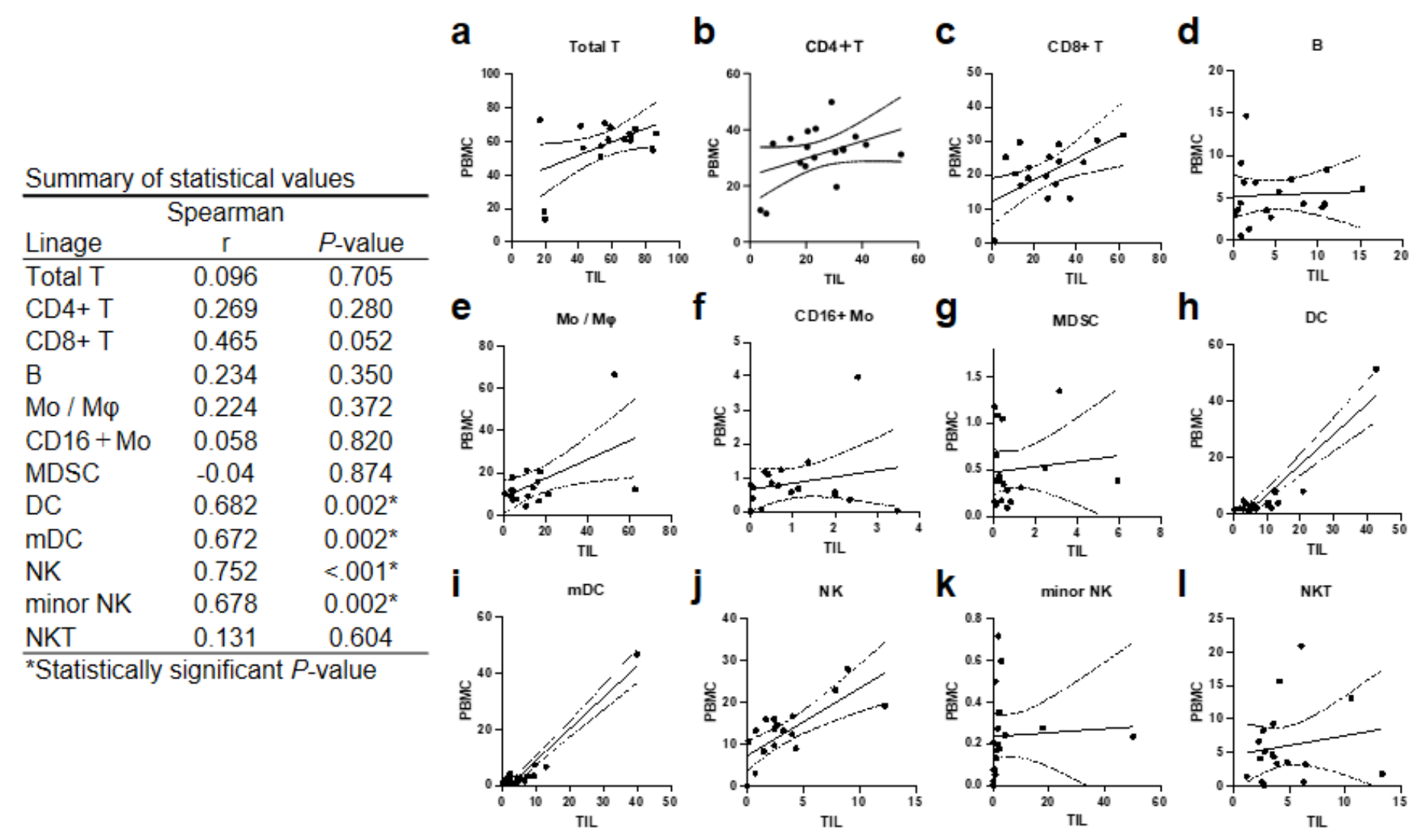

Figure 2

Immune cell composition of blood is partly correlated with that of tumor tissue. (a-l) For cases with matched samples of blood and tumor tissues, a correlation analysis was performed for the percentage of each immune cell fraction. The $\mathrm{X}$ - and $\mathrm{Y}$-axes show the percentage of immune cell fractions for the tumor tissue (TIL) and blood (PBMC), respectively. The lines in the graph indicate the regression line with a 95\% confidence band. The relationship between these values was analyzed using the Spearman correlation. Values of $P<0.05$ were considered statistically significant. Statistical values are summarized in the table on the left side of the figure 


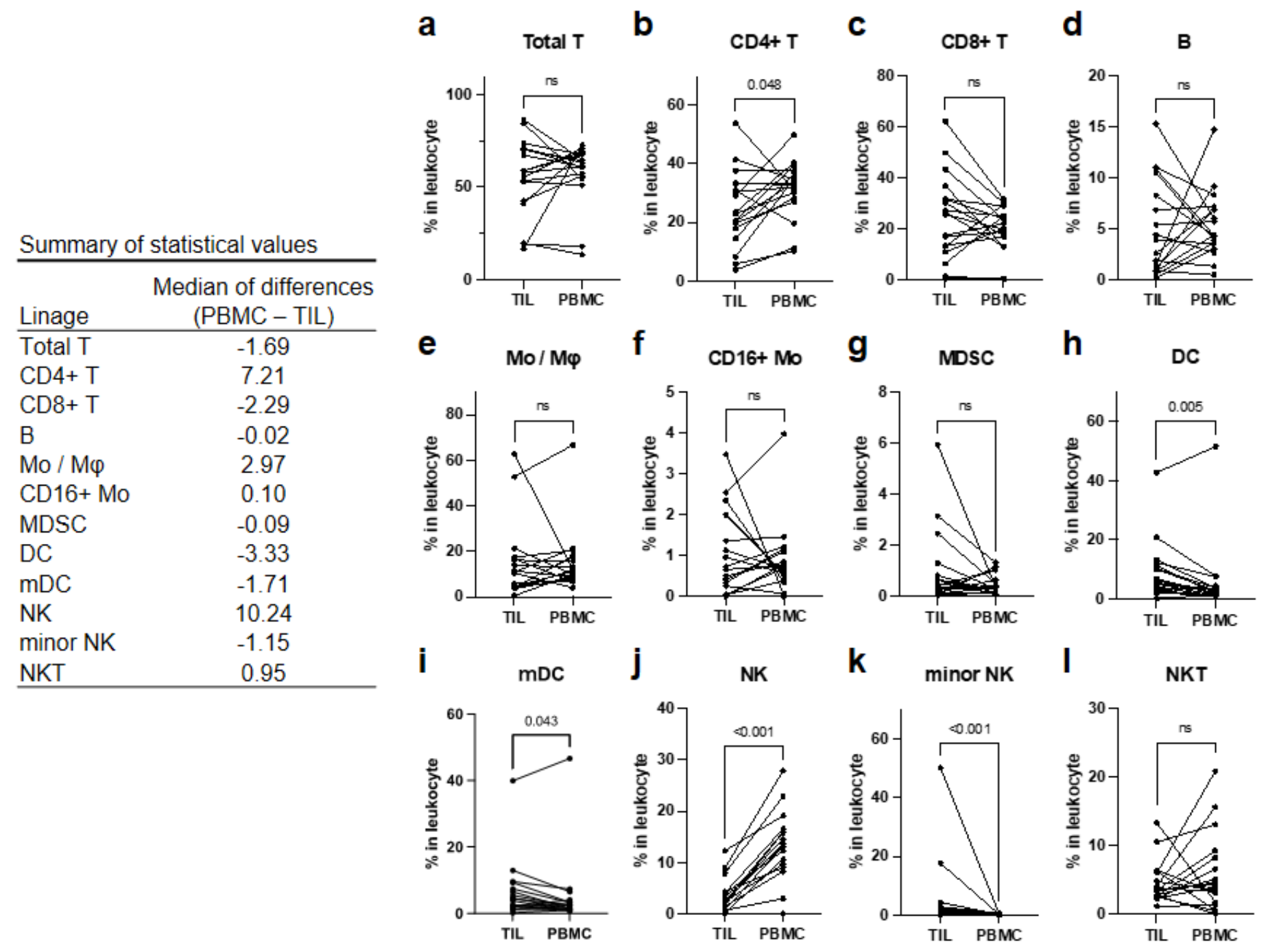

Figure 3

Percentage of immune cell fractions is partly different between tumor tissue and blood. (a-l) For 18 cases with matched samples of blood and tumor tissues, the percentages of each immune cell fraction of tumor tissues (TIL) and blood (PBMC) were compared using the Wilcoxon test. Values of $\mathrm{P}<0.05$ were considered to be statistically significant. The actual P-values are shown in the graphs. The medians of the differences are summarized in the table on the left side of the figure 
a

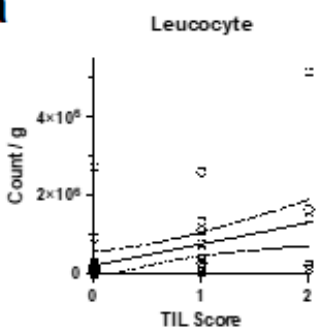

Summary of statistical values

\begin{tabular}{lcc}
\hline & Spearman $\mathrm{r}$ & $P$-value \\
\hline Leucocyte & 0.547 & $<.001^{*}$ \\
Total T & 0.405 & $0.006^{*}$ \\
CD4+ T & 0.316 & $0.037^{*}$ \\
CD8+ T & 0.323 & $0.032^{*}$ \\
B & 0.163 & 0.289 \\
Mo / M $\varphi$ & -0.286 & 0.060 \\
CD16+ Mo & -0.036 & 0.816 \\
MDSC & -0.080 & 0.605 \\
DC & -0.207 & 0.178 \\
mDC & -0.290 & 0.056 \\
NK & -0.495 & $0.001^{*}$ \\
minor NK & 0.022 & 0.886 \\
NKT & -0.472 & $0.001^{*}$ \\
\hline NST
\end{tabular}

${ }^{*}$ Statistically significant $P$-value
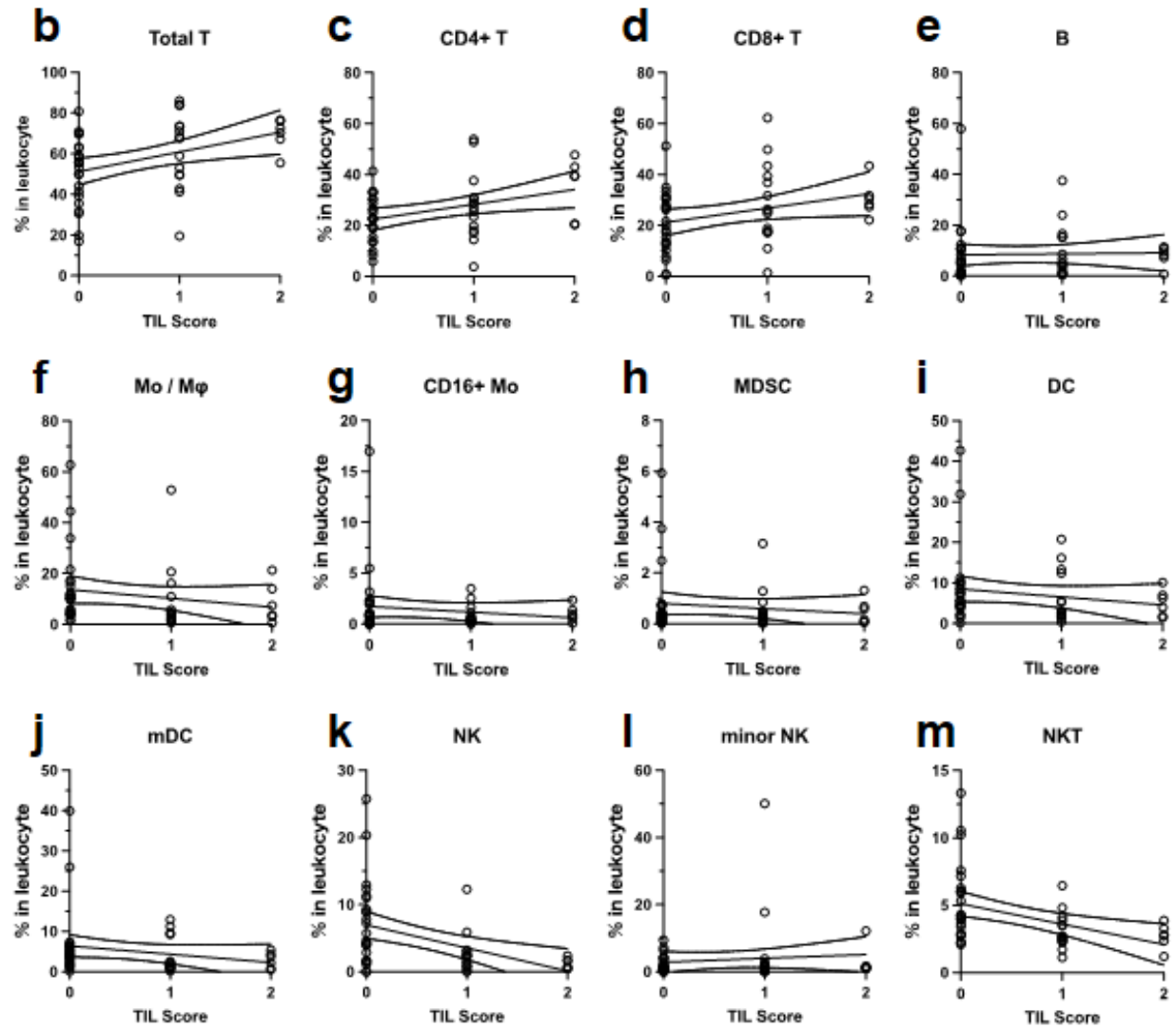

\section{Figure 4}

hTIL was associated with the degree of leukocyte infiltration in tumor tissue and leukocyte composition. For cases with tumor tissue samples, a correlation analysis was performed for (a) hTIL scores and leukocyte densities (count/g) in tumor tissues, and $(b-m)$. The hTIL scores and percentages of each immune cell fraction in the tumor tissues. The X-and Y-axis show the hTIL scores and (a) leukocyte densities (count/g) or $(b-m)$ the percentages of the immune cell fractions in the tumor tissue. The lines in the graph indicate the regression line with a 95\% confidence band. The relationship between these values was analyzed using a Spearman correlation. Values of $P<0.05$ were considered statistically significant. Statistical values are summarized in the table on the left side of the figure

\section{Figure 5}

PD-L1 is preferentially expressed in part of the immune cell fraction, and higher in tumor-infiltrating leukocytes than in blood. The percentages of PD-L1 positive cells of each immune cell fraction were determined for the tumor tissues (TIL) and blood (PBMC). (a) For the tumor tissue samples, the percentages of PD-L1 positive cells in each immune cell fraction are shown using Tukey box plots. (b-l) For the cases with matched samples of blood and tumor tissue, the percentages of PD-L1 positive cells of each immune cell fraction were compared for the tumor tissue (TIL) and that of blood (PBMC) using 
the Wilcoxon test. Values of $\mathrm{P}<0.05$ were considered statistically significant. The actual P-values are shown in the graphs. The median of the differences is summarized in the table on the left side of the figure

\section{Figure 6}

hPD-L1 positivity was associated with increased leukocyte infiltrations in the tumor tissue and partly with the immune cell composition. For cases with tumor tissue samples, (a) leukocyte densities (count/g) and $(b-m)$ the percentages of the immune cell fractions in the tumor tissues were compared between the hPD-L1-negative cases and hPD-L1 positive cases using the Mann-Whitney U test. The data are presented using Tukey box plots. Values of $\mathrm{P}<0.05$ were considered to be statistically significant. The actual Pvalues are shown in the graphs

\section{Figure 7}

hPD-L1 positivity was associated with PD-L1 positive ratio in part of the immune cell fraction. (a-k) For cases with tumor tissue samples, the percentages of PD-L1 positive cells in each immune cell fraction of the tumor tissues in the hPD-L1-negative cases and hPD-L1 positive cases were compared using the Mann-Whitney $U$ test. The data are presented using Tukey box plots. Values of $P<0.05$ were considered to be statistically significant. The actual P-values are presented in the graphs

\section{Supplementary Files}

This is a list of supplementary files associated with this preprint. Click to download.

- Fig.S1.pptx

- Fig.S2.pptx

- Fig.S3.pptx

- Fig.S4.pptx

- Fig.S5.pptx

- Fig.S6.pptx

- Supplementarytables.docx 